\title{
Controle de Meloidogyne incognita em tomateiro pelo extrato de crambe em diferentes formas de aplicação
}

\author{
Sidiane Coltro-Roncato ${ }^{1}$, José Renato Stangarlin², Odair José Kuhn², Affonso Celso Gonçalves Júnior ${ }^{2}$,Omari Dangelo
} Forlin Dildey ${ }^{1}$, Edilaine Della Valentina Gonçalves ${ }^{1}$, Bruna Broti Rissato ${ }^{1}$, Laline Broetto ${ }^{1}$, Vanessa de Oliveira Faria ${ }^{1}$

${ }^{1}$ Discentes da Pós-graduação em Produção Vegetal, Laboratório de Nematologia e Fitopatologia, Universidade Estadual do Oeste do Paraná (UNIOESTE), Campus Marechal Cândido Rondon, Marechal Cândido Rondon, PR, Brasil, CEP: 85960-000. ${ }^{2}$ Docentes, Centro de Ciências Agrárias, UNIOESTE, Campus Marechal Cândido Rondon, Marechal Cândido Rondon, PR, Brasil.

Autora para correspondência: Sidiane Coltro-Roncato (scoltr@hotmail.com)

Data de chegada: 04/05/2017. Aceito para publicação em: 02/10/2017.

$10.1590 / 0100-5405 / 179533$

\section{RESUMO}

Coltro-Roncato, S.; Stangarlin, J.R.; Kuhn, O.J.; Gonçalves Júnior, A.C.; Dildey, O.D.F.; Gonçalves, E.D.V.; Rissato, B.B.; Broetto, L.; Faria, V.O. Controle de Meloidogyne incognita em tomateiro pelo extrato de crambe em diferentes formas de aplicação. Summa Phytopathologica, v.44, n.3, p.261-266, 2018.

O crambe pode ser uma alternativa viável no controle de fitonematoides. O objetivo do presente trabalho foi avaliar qual o melhor método de aplicação do extrato de Crambe abyssinica no controle de Meloidogyne incognita. O primeiro experimento foi conduzido em esquema fatorial $(3 \times 4+1)$ em casa de vegetação, com três vias de aplicação do extrato (foliar; solo; foliar+solo), em quatro épocas de aplicação (antes da inoculação; na inoculação; após a inoculação; e semanalmente até 45 dias após a inoculação), e com um tratamento adicional (testemunha). No segundo experimento, o esquema fatorial foi $(3 \times 2+1)$, com três vias de aplicação como citado anteriormente, e duas épocas (após a inoculação e semanalmente). A via foliar após a inoculação e a via solo semanalmente reduziram $23,50 \%$ e $30,77 \%$ a massa de ovos em comparação à testemunha, respectivamente. A redução do número de galhas com aplicações semanais tanto via solo como via solo+folha foi de $49,27 \%$ em comparação à testemunha. No segundo experimento, menos massa de ovos e galhas totais foram verificadas em aplicações via solo semanalmente. A redução de juvenis de segundo estádio (J2) e ovos por grama de raiz foi observada após a inoculação pela via solo+folha, e semanalmente via solo e via solo+folha, com valores $55,24 \%, 61,57 \%$ e $60 \%$ inferior à testemunha, respectivamente. $\mathrm{O}$ extrato de crambe aplicado via solo semanalmente foi promissor para o manejo de $M$. incognita na cultura do tomateiro.

Palavras-chave: Crambe abyssinica, nematoide de galhas, nematicida.

\section{ABSTRACT}

Coltro-Roncato, S.; Stangarlin, J.R.; Kuhn, O.J.; Gonçalves Júnior, A.C.; Dildey, O.D.F.; Gonçalves, E.D.V.; Rissato, B.B.; Broetto, L.; Faria, V.O. Control of Meloidogyne incognita in tomato by crambe extract using different application forms. Summa Phytopathologica, v.44, n.3, p.261-266, 2018.

Crambe may be a viable alternative in the control of plant nematodes. The aim of the present study was to evaluate the best method for applying Crambe abyssinica extract to control Meloidogyne incognita. The first experiment was conducted in a $(3 \times 4+1)$ factorial design in a greenhouse, using three modes of extract application (leaf; soil; leaf + soil), in four times of application (before inoculation; during inoculation; after inoculation; and weekly until 45 days after inoculation), with an additional treatment (control). In the second experiment, factorial design was $(3 \times 2+1)$, with three application modes, as mentioned above, and two times of application (after inoculation and weekly). Application on the leaf after inoculation and weekly application on the soil reduced egg mass by $23.50 \%$ and $30.77 \%$, respectively, compared to control. The reduction in the number of root-knots with weekly applications both on the soil and on the soil + leaf was $49.27 \%$, compared to control. In the second experiment, less egg mass and total rootknots were verified with weekly applications. Second-stage juveniles (J2) and eggs per gram of root reduced after inoculation via soil + leaf and weekly inoculation via soil and via soil + leaf, showing values $55.24 \%, 61.57 \%$ and $60 \%$ lower than those of control, respectively. Crambe extract weekly applied on the soil showed promising for the management of $M$. incognita in tomato plants.

Keywords:Crambe abyssinica, root-knot nematode, nematicide.

A utilização de compostos de origem vegetal pode ser uma alternativa promissora no manejo de fitonematoides, pois várias espécies de plantas apresentam efeito nematicida contra Meloidogyne incognita (Kofoid \& White) Chitwood devido a presença de metabólitos nematicidas, como Cinnamomum cassia (Koehler) (6) e Eucalyptus exserta F. Muell (13). Espécies de Brassicas produzem glicosinolatos e seus derivados, após hidrólise enzimática, possuem atividade biológica contra nematoides, fungos e outros patógenos veiculados pelo solo (20).

O crambe (Crambe abyssinica Hochst ex Fries), uma planta da família Brassicaceae, também se enquadra neste contexo por apresentar glicosinolatos, é uma planta anual e uma cultura que ao longo dos últimos anos vem sendo introduzido em muitos países, como nova 
fonte de óleo (teor de óleo de 35\%), contendo alto teor de ácido erúcico com alto valor para fins industriais com menor impacto ambiental (7).

Extratos vegetais podem controlar nematoides não exclusivamente pelo efeito nematicida e/ou nematostático, mas também por outros mecanismos de proteção às plantas que podem estar envolvidos (7). A raiz é o local principal para abrigo e sustento de fitonematoides, local este protegido muitas vezes do contato ou do sítio de aplicação de produtos nematicidas. Assim sendo, indutores de resistência podem favorecer o manejo destes organismos, por permitirem que as respostas de defesa da planta se manifestem exatamente no local da infecção, além de serem produtos ambientalmente corretos por não possuírem efeitos tóxicos diretos a organismos não alvos (21). No entanto, os indutores de resistência podem variar sua ação de proteção da planta em função da formulação do produto fornecido, do método de aplicação, da fenologia e sanidade das plantas e condições ambientais (17).

A maioria dos estudos envolvendo Brássicas no controle de nematoides trabalha com a biofumigação, com incorporação do material vegetal fresco ou seco no solo para posterior liberação de compostos biocidas $(16,20)$. Aissani et al. (1) verificaram o efeito nematicida do extrato de Brassica (Armoracia rusticana) contra Meloidogyne incognita e atribuíram o efeito aos isotiocianatos. O crambe contém glicosinolatos, e o pó produzido a partir desta brássica demonstrou toxidez à nematoides (12). Sendo assim, este trabalho concentra-se no potencial de utilização do extrato vegetal de Crambe abyssinica no controle de $M$. incognita em tomateiro, por meio de diferentes métodos de aplicação.

\section{MATERIAL E MÉTODOS}

Foram conduzidos dois experimentos em casa de vegetação, o primeiro nos meses de abril à junho de 2014 e o segundo nos meses de outubro à dezembro de 2014. O delineamento experimental foi em blocos casualizados com cinco repetições. $\mathrm{O}$ extrato utilizado foi o hidroalcoólico $250 \mathrm{mg} \mathrm{L}^{-1}$ preparado segundo a metodologia proposta por Loguercio et al. (14), na qual, as folhas secas de crambe em estufa a $45^{\circ} \mathrm{C}$ por $48 \mathrm{~h}$ foram trituradas e armazenadas em recipiente fechado por 15 dias em solução hidroalcoólica ( $70 \%$ v/v álcool etílico).

Foram utilizadas mudas de tomateiro Santa Cruz Kada (Paulista) com 25 dias após a semeadura, cultivadas em bandejas com substrato, e transplantadas em vasos com capacidade de três litros preenchidos com solo esterilizado na mistura 3:2:1 (solo:areia:matéria orgânica). O inóculo de $M$. incognita foi obtido de tomateiros infectados cultivados em casa de vegetação climatizada, a temperatura média foi de aproximadamente $25^{\circ} \mathrm{C}$.

As variáveis foram analisadas 45 dias após inoculação. Após a separação das raízes do solo, estas foram lavadas e secas em temperatura ambiente para pesagem da massa fresca da raiz, e armazenadas em sacos plásticos, tanto as raízes como o solo separadamente, em temperatura próxima aos $4{ }^{\circ} \mathrm{C}$. Foram avaliados o número de ovos e J2 por 100 $\mathrm{cm}^{3}$ de solo e por grama de raiz, número de galhas e massa de ovos nas raízes.

O método flotação centrífuga em solução de sacarose foi empregado para extração de ovos e nematoides do solo (11). Para extração de ovos e nematoides das raízes foi utilizado a metodologia de Freitas et al. (10). Os ovos e $\mathrm{J} 2$ retidos na peneira de 400 mesh foram transferidos para lâmina de Peters e quantificado com microscópio óptico. Para verificar a existência de massa de ovos nas raízes, estas foram coradas com Floxina B (23), e contados galhas com massa de ovos e sem massa de ovos com auxílio de lupa de mesa, a soma de ambas gerou o número de galhas totais.

\section{Primeiro experimento}

O esquema fatorial $(3 \times 4+1)$ foi utilizado, sendo, três diferentes vias de aplicação na planta: via solo, via foliar e via solo+foliar, em quatro épocas de aplicação: 1) antes da inoculação (três dias após o transplante das mudas); 2) na inoculação (sete dias após o transplante); 3) após a inoculação (uma semana após a inoculação); e 4) semanalmente até aos 45 dias após a inoculação, totalizando nove aplicações (incluindo todas as épocas de aplicação citadas anteriormente), além de um tratamento adicional, representado pela testemunha inoculada e não tratada.

Para o tratamento via foliar as folhas foram pulverizadas até ponto de escorrimento, mas sem o extrato entrar em contato com o solo, pois a superfície do vaso foi coberta com jornal. As plantas tratadas via solo receberam $30 \mathrm{~mL}$ do extrato por vaso, correspondendo à $1 \%$ do volume do vaso. Todos os tratamentos foram efetuados no período da manhã. Após sete dias do transplante foi efetuada a inoculação com uma suspensão de ovos e J2, com 5.000 ovos e $500 \mathrm{~J} 2$ por vaso de $M$. incognita, em orifícios próximos à raiz.

\section{Segundo experimento}

Após análise dos dados do primeiro experimento, foi conduzido um segundo experimento para confirmação das melhores épocas de aplicação. Utilizou-se o esquema fatorial $(3 \times 2+1)$, com três vias de aplicação na planta, como citado no primeiro experimento, e duas épocas de aplicação: 1) após inoculação; e 2) semanalmente. Foram inoculados aproximadamente 5.000 ovos e $900 \mathrm{~J} 2$ por vaso.

Após a contagem do número de massa de ovos e galhas totais, as massas de ovos foram coletadas para avaliar a viabilidade dos ovos. Para tanto foram utilizadas três repetições por tratamento e em triplicata, em delineamento inteiramente casualizado, onde placas de Elisa com água destilada foram utilizadas. Em cada pocinho foi colocado $350 \mu \mathrm{L}$ de água e uma massa de ovos e após 15 dias foi avaliada a eclosão dos J2.

Para ambos os ensaios, para análise dos dados foi realizado o teste de normalidade de Lilliefors à $5 \%$ de probabilidade, e em todos os dados foi aplicado o teste Q, ficando com quatro repetições, ainda para algumas variáveis como massa de ovos do primeiro experimento, os valores foram transformados em $\sqrt{x+0.5}$, e para massa de ovos e galhas totais do segundo experimento os valores foram transformados em $\log (\mathrm{x}+1)$. Posteriormente, realizou-se a análise de variância e as médias foram submetidas ao teste de Tukey, e quando o tratamento adicional mostrava-se significativo na análise de variância utilizou-se um teste adicional, o Dunnett. O software estatístico utilizado foi o Genes (5).

\section{RESULTADOS E DISCUSSÃO}

Aplicações semanalmente pela via solo+folha resultaram em $33,35 \%$ menos de massa de ovos do que a mesma via de aplicação após a inoculação, e inferiores $52,70 \%$ e $29 \%$ comparados a testemunha, respectivamente (Tabela 1 ).

Comparando as aplicações via foliar após a inoculação com a via solo semanalmente, observa-se que os tratamentos via solo requerem mais aplicações para um efetivo controle dos nematoides. Isto ocorre provavelmente porque após a inoculação, momento em que foi aplicado o tratamento, os $\mathrm{J} 2$ já pudessem ter penetrado nas raízes, não havendo assim o efeito direto do extrato no patógeno. Por outro lado, no 
Tabela 1. Massa de ovos em raízes de tomateiro inoculados com Meloidogyne incognita, na qual as raízes das plantas de tomateiro foram tratadas com extrato de Crambe abyssinica, e as mesmas plantas receberam o extrato em diferentes vias e em épocas distintas de aplicação.

\begin{tabular}{|c|c|c|c|c|}
\hline \multirow{2}{*}{ Vias de aplicação do extrato } & \multicolumn{4}{|c|}{ Épocas de aplicação } \\
\hline & Antes da inoculação & Na inoculação & Após a inoculação & Semanalmente \\
\hline Solo & 1178,25 Aa $\alpha$ & 1170,75 Aa $\alpha$ & 1147,00 Аа $\alpha$ & $551,00 \mathrm{Bb}$ \\
\hline Folha & $1068,00 \mathrm{Aa} \alpha$ & 1301,00 Аа $\alpha$ & $666,50 \mathrm{Bb}$ & 1146,00 Аа $\alpha$ \\
\hline Solo + Folha & $990,75 \mathrm{Ba} \alpha$ & 1291,00 Аa $\alpha$ & $807,25 \mathrm{Bb}$ & $538,00 \mathrm{Cb}$ \\
\hline Testemunha & \multicolumn{4}{|c|}{$1137,50 \alpha$} \\
\hline CV (\%) & 7,85 & 3,58 & 6,97 & 7,19 \\
\hline
\end{tabular}

Médias seguidas pelas mesmas letras maiúsculas na horizontal e minúsculas na vertical não diferem estatisticamente entre si pelo teste de Tukey a $5 \%$ de probabilidade. ${ }^{\omega}$ Médias não diferem do tratamento adicional pelo teste de Dunnett ao nível de $5 \%$ de probabilidade

tratamento via foliar, mesmo que o J2 já tivessem penetrado, a planta reagiria com mecanismos de defesa induzidos pelo extrato, prejudicando a reprodução e, consequentemente, resultando em menos massa de ovos. Segundo Molinari \& Baser (17), a aplicação do indutor de resistência ASM (acibenzolar-S-metil) não inibiu a penetração e formação de sítios de alimentação, mas sim a reprodução dos nematoides. Segundo Oka $\&$ Cohen (18), a aplicação de ácido DL- $\beta$-amino- $n$-butírico (BABA) em plantas de tomateiro até 16 dias após a inoculação do nematoide, foi eficaz na redução de massa de ovos de Meloidogyne em função do mecanismos de resistência que foram induzidos.

O tratamento via solo exige mais aplicações, desde o início do cultivo até o final, para que assim, o solo sempre tenha presente os compostos nematicidas e/ou nematostáticos do extrato, fazendo com que o J2 atrase ou não penetre na raiz. As condições ambientais e a estabilidade de compostos presentes nos extratos derivados de plantas podem afetar os mecanismos de ação destes, degradando-os rapidamente no solo, exigindo assim, várias aplicações (22).

Espécies de Brássicas possuem glicosinolatos, que são hidrolisados em isotiocianatos, nitrilas, tiocianatos e epinitrilas. No entanto, a supressão de patógenos no solo está relacionada com a liberação de isotiocianato (15). Os isotiocianatos são compostos voláteis, por isso são muito utilizados como biofumigantes, e a vida útil no solo é geralmente curta. A estabilidade do alil isotiocianato em seis tipos de solo variou de 20 a 60 horas, o que pode ser vantajoso quando se tratando de impactos ambientais, mas desvantajoso por não estar presente em tempo suficiente para produzir o efeito desejado sobre as pragas (1, 19). Segundo Wu et al. (24), produtos sintetizados a partir de Brássicas apresentam efeito nematicida contra $M$. javanica e tem potencial para serem usados como bio-fumigantes, e sem perigos de aplicação.

O uso do extrato de crambe via solo foi efetivo na redução de galhas totais de $M$. incognita quando aplicado semanalmente (Tabela 2). A via foliar apresentou controle somente na época após a inoculação.
Nas épocas anteriores como antes da inoculação, talvez por ser um período de adaptação da planta ao transplante, pode não ter ocorrido o reconhecimento do indutor, e assim, no momento da inoculação, a ativação dos mecanismos de defesa vegetal tenha sido pequena e sem efeito no ciclo do nematoide.

O número de aplicações foliares depende do tipo de indutor, pois Oka \& Cohen (18) observaram correlação negativa entre o número de aplicações foliares do BABA (num intervalo de dez dias, iniciando dois dias antes da inoculação) e o número de cistos de Heterodera avenae Woll. em trigo. Ainda, os mesmos autores observaram que os $\mathrm{J} 2$ de $H$. avenae penetraram em raízes de trigo tratadas via solo com BABA e induziram sítios de alimentação, demonstrando assim, que o BABA não tem ação nematicida, mas atua ativando mecanismos de defesa na planta.

Alguns extratos vegetais podem promover a morte de $\mathrm{J} 2$. Tal fato é atribuído a danos ocasionados na cutícula externa do nematoide pelos compostos presentes no extrato, além de promover inibição da enzima V-ATPase, fazendo com que o nematoide fique paralisado e acabe morrendo (4). De acordo com Babu et al. (3), alguns fitoquímicos derivados de plantas apresentam efeito nematicida, e este efeito na mortalidade de M. incognita está relacionado a inibição de glutationa-Stransferase, que é uma enzima importante no metabolismo do nematoide por atuar no sistema de defesa. Andrade et al. (2) observaram que uma proteína produzida por crotalária inibe a papaína, uma importante enzima relacionada a digestão de $M$. incognita.

Tratamentos via solo+folha semanalmente foram $46 \%$ mais efetivos em reduzir o número de galhas comparado com o tratamento na época antes da inoculação, e esta não diferiu da testemunha. $\mathrm{O}$ tratamento após a inoculação foi intermediário e não diferiu estatisticamente das aplicações semanais e antes da inoculação (Tabela 2).

Estudos realizado por Franzener et al. (8), utilizando extrato de flores de Tagetes patula L. no controle de M. incognita em tomateiro,

Tabela 2. Galhas totais em raízes de tomateiro inoculados com Meloidogyne incognita, na qual as raízes das plantas de tomateiro foram tratadas com extrato de Crambe abyssinica, e as mesmas plantas receberam o extrato em diferentes vias e em épocas distintas de aplicação.

\begin{tabular}{|c|c|c|c|c|}
\hline \multirow{2}{*}{ Vias de aplicação do extrato } & \multicolumn{4}{|c|}{ Épocas de aplicação } \\
\hline & Antes da inoculação & Na inoculação & Após a inoculação & Semanalmente \\
\hline Solo & 1561,75 Aa $\alpha$ & 1665,25 Aa $\alpha$ & 1581,75 Aa $\alpha$ & $710,50 \mathrm{Bb}$ \\
\hline Folha & 1543,25 Аа $\alpha$ & $1724,00 \mathrm{Aa}$ & $899,75 \mathrm{Bb}$ & 1542,75 Аа $\alpha$ \\
\hline Solo + Folha & $1317,25 \mathrm{Ba} \alpha$ & $1739,00 \mathrm{Aa}$ & $1018,00 \mathrm{BCb}$ & $710,50 \mathrm{Cb}$ \\
\hline Testemunha & \multicolumn{4}{|c|}{$1400,50 \alpha$} \\
\hline CV (\%) & 17,75 & 3,83 & 14,66 & 14,52 \\
\hline
\end{tabular}

Médias seguidas pelas mesmas letras maiúsculas na horizontal e minúsculas na vertical não diferem estatisticamente entre si pelo teste de Tukey a $5 \%$ de probabilidade. Médias não diferem do tratamento adicional pelo teste de Dunnett ao nível de $5 \%$ de probabilidade 
demonstraram que houve diferença entre as épocas de aplicação, com melhor efeito para o extrato aplicado semanalmente, tanto quando aplicado na folha como no solo ou em ambos concomitantemente, resultando em redução de $62,2 \%$ de galhas, em $61,5 \%$ do número de juvenis no solo e em 52,8\% do número de ovos nas raízes de tomateiro, e que apenas uma aplicação não apresentou efeito na proteção do tomateiro.

Conforme apresentado no primeiro experimento, os tratamentos nas épocas após a inoculação e semanalmente foram os mais eficientes na redução do número de massa de ovos e galhas totais, e, portanto, foram analisadas novamente no segundo experimento.

A massa de ovos no segundo experimento (Tabela 3) não diferiu entre as vias de aplicação e épocas, assim como as galhas totais, porém, aplicações semanais via solo diferiram da testemunha com $69,80 \%$ menos de massa de ovos e $63,84 \%$ menos galhas totais. Estes resultados confirmam os encontrados no experimento anterior, na qual tratamentos via solo tem efeito quando aplicados semanalmente, e podem atuar diretamente no nematoide.

O número de galhas e de massa de ovos de $M$. incognita foi reduzido em tomateiros tratados com farinha de semente e de folhas da Brassica juncea L. incorporada ao solo, com controle de $95 \%$ a $99 \%$. As diferenças entre os tratamentos testados foram devido ao conteúdo de alil isotiocianato liberado no solo, por meio da mortalidade de juvenis e repressão da eclosão de ovos (20).

As variáveis $\mathrm{J} 2$ e ovos por grama de raiz do primeiro experimento diferiram entre as épocas de aplicação apenas para o tratamento via foliar, sendo a maior média $(435,47)$ na época antes da inoculação, enquanto as demais foram inferiores e não diferiram estatisticamente entre si (Tabela 4).

$\mathrm{O}$ extrato de crambe demonstrou-se efetivo no controle de $M$. incognita, pois, na maioria dos tratamentos, houve redução destas variáveis (J2 e ovos) comparado à testemunha. Além disso, pode-se observar que existem diferenças entre as vias de aplicação para cada época, como por exemplo, na época antes da inoculação, a aplicação via solo apresentou menor média comparada as outras vias, e 48,62\% inferior à testemunha. Para o tratamento na inoculação, a menor média observada foi na aplicação via foliar, com valor 53,56\% inferior a testemunha. Após a inoculação o tratamento via solo+folha foi $55,24 \%$ inferior à testemunha e semanalmente via solo e via solo+folha não diferiram entre si, mas com valores $36 \%$ e 33,30\% inferior à aplicação via foliar, respectivamente, e $61,57 \%$ e $60 \%$ inferior à testemunha (Tabela 4).

Sugere-se que aplicações semanais resultam em controle pelo efeito tóxico do extrato no solo, fazendo com que os J2 tornem-se imóveis ou mortos, com menor penetração e ciclos, gerando menor população, embora também não se descarte o efeito indutor de resistência. Extratos de T. patula podem ativar mecanismos de defesa em raízes de tomateiro contra $M$. incognita, tanto por meio de aplicações na parte aérea como no solo, uma vez que esta ativação pode ser local ou sistêmica (9).

De acordo com a Tabela 5, para a aplicação via foliar, a época após a inoculação apresentou redução de $70,97 \%$ de J2 e ovos por $100 \mathrm{~cm}^{3} \mathrm{de}$ solo comparado a época antes da inoculação. As demais épocas foram

Tabela 3. Massa de ovos (MO) e galhas totais (GT) em raízes de tomateiro inoculados com Meloidogyne incognita, na qual a planta foi tratada com extrato de Crambe abyssinica em diferentes vias e em épocas distintas de aplicação.

\begin{tabular}{|c|c|c|c|c|}
\hline \multirow{2}{*}{ Vias de aplicação do extrato } & \multicolumn{2}{|c|}{ MO $^{\text {ns }}$} & \multicolumn{2}{|c|}{ GT $^{\text {ns }}$} \\
\hline & Após a inoculação & Semanalmente & Após a inoculação & Semanalmente \\
\hline Solo & $291,25 \alpha$ & 168,25 & $315,00 \alpha$ & 201,50 \\
\hline Folha & $453,50 \alpha$ & $317,75 \alpha$ & $525,75 \alpha$ & $353,50 \alpha$ \\
\hline Testemunha & \multicolumn{2}{|c|}{$557,25 \alpha$} & \multicolumn{2}{|c|}{$630,50 \alpha$} \\
\hline CV $(\%)$ & 9,17 & 12,62 & 8,98 & 12,41 \\
\hline
\end{tabular}

${ }^{n}$ Médias não diferem estatisticamente entre si pela análise de variância. ${ }^{\alpha}$ Médias não diferem do tratamento adicional pelo teste de Dunnett ao nível de $5 \%$ de probabilidade

Tabela 4. Ovos e juvenis de segundo estádio (J2) de Meloidogyne incognita por grama de raiz, na qual as raízes das plantas de tomateiro foram tratadas com extrato de Crambe abyssinica, e as mesmas plantas receberam o extrato em diferentes vias e em épocas distintas de aplicação.

\begin{tabular}{lccc}
\hline Vias de aplicação do extrato & \multicolumn{2}{c}{ Épocas de aplicação } & Após a inoculação \\
\hline Solo & Antes da inoculação & Na inoculação & $216,64 \mathrm{Aa}$ \\
Folha & $228,20 \mathrm{Ac}$ & $239,24 \mathrm{Ab}$ & $216,09 \mathrm{Ba}$ \\
Solo + Folha & $435,47 \mathrm{Aa} \alpha$ & $206,25 \mathrm{Bc}$ & $170,67 \mathrm{Ab}$ \\
\hline Testemunha & $283,11 \mathrm{Ab} \alpha$ & $261,63 \mathrm{Aa}$ & $\mathrm{Ab}$ \\
\hline $\mathrm{CV}(\%)$ & & $444,15 \alpha$ & $177,65 \mathrm{Ab}$ \\
\hline
\end{tabular}

Médias seguidas pelas mesmas letras maiúsculas na horizontal e minúsculas na vertical não diferem estatisticamente entre si pelo teste de Tukey a $5 \%$ de probabilidade. ${ }^{\alpha}$ Médias não diferem do tratamento adicional pelo teste de Dunnett ao nível de 5\% de probabilidade 
Tabela 5. Ovos e juvenis de segundo estádio (J2) de Meloidogyne incognita por $100 \mathrm{~cm}^{3}$ de solo, na qual as raízes das plantas de tomateiro foram tratadas com extrato de Crambe abyssinica, e as mesmas plantas receberam o extrato em diferentes vias e em épocas distintas de aplicação.

\begin{tabular}{|c|c|c|c|c|}
\hline \multirow{2}{*}{ Vias de aplicação do extrato } & \multicolumn{4}{|c|}{ Épocas de aplicação } \\
\hline & Antes da inoculação & Na inoculação & Após a inoculação & Semanalmente \\
\hline Solo & 756,00 Аа $\alpha$ & 1078,80 Аа $\alpha$ & 1082,40 Аа $\alpha$ & 974,40 Aa $\alpha$ \\
\hline Solo + Folha & 1113,60 Аа $\alpha$ & 718,80 Aa $\alpha$ & $472,80 \mathrm{Aab}$ & 776,40 Аа $\alpha$ \\
\hline Testemunha & \multicolumn{4}{|c|}{$1089,60 \alpha$} \\
\hline
\end{tabular}

Médias seguidas pelas mesmas letras maiúsculas na horizontal e minúsculas na vertical não diferem estatisticamente entre si pelo teste de Tukey a $\%$ de probabilidade. ${ }^{\alpha}$ Médias não diferem do tratamento adicional pelo teste de Dunnett ao nível de $5 \%$ de probabilidade

Tabela 6. Ovos e juvenis de segundo estádio (J2) de Meloidogyne incognita por grama de raiz e por $100 \mathrm{~cm}^{3}$ de solo, na qual a planta foi tratada com extrato de Crambe abyssinica em diferentes vias e em épocas distintas de aplicação.

\begin{tabular}{|c|c|c|c|c|}
\hline \multirow{3}{*}{$\begin{array}{l}\text { Vias de aplicação do extrato } \\
\text { Após a inoculação }\end{array}$} & \multicolumn{2}{|c|}{ J2 e ovos por grama de raiz } & \multicolumn{2}{|c|}{$\mathrm{J} 2 \mathrm{e}$ ovos por $100 \mathrm{~cm}^{3}$ de solo } \\
\hline & \multicolumn{4}{|c|}{ Épocas de aplicação } \\
\hline & Semanalmente & Após a inoculação & Semanalmente & \\
\hline Folha & 2636,79 Аа $\alpha$ & 1883,35 Аа $\alpha$ & $1488,00 \mathrm{Aab} \alpha$ & $1191,60 \mathrm{Ab}$ \\
\hline Solo + Folha & $1205,76 \mathrm{Ab}$ & $576,01 \mathrm{Ab}$ & $1098,35 \mathrm{Ab}$ & $1932,00 \mathrm{Aab} \alpha$ \\
\hline CV (\%) & 31,82 & 37,42 & 27,93 & 28,91 \\
\hline
\end{tabular}

Médias seguidas pelas mesmas letras maiúsculas na horizontal e minúsculas na vertical não diferem estatisticamente entre si pelo teste de Tukey a $\%$ de probabilidade. ${ }^{\alpha}$ Médias não diferem do tratamento adicional pelo teste de Dunnett ao nível de 5\% de probabilidade

Tabela 7. Viabilidade de massa de ovos de Meloidogyne incognita, na qual a planta de tomateiro foi tratada com extrato de Crambe abyssinica em diferentes vias e em épocas distintas de aplicação.

\begin{tabular}{lcc}
\hline & Vias de aplicação do extrato & J2 eclodidos dos ovos \\
Solo & Épocas de aplicação & Semanalmente \\
Folha & Após a inoculação & $248,50 \mathrm{Aa}$ \\
Solo + Folha & $255,67 \mathrm{Ab} \alpha$ & $228,78 \mathrm{Ba}$ \\
\hline Testemunha & $404,89 \mathrm{Aa} \alpha$ & $202,00 \mathrm{Ba}$ \\
\hline CV $(\%)$ & $358,55 \mathrm{Aab} \alpha$ & $357,00 \alpha$ \\
\hline
\end{tabular}

Médias seguidas pelas mesmas letras maiúsculas na horizontal e minúsculas na vertical não diferem estatisticamente entre si pelo teste de Tukey a $5 \%$ de probabilidade.

${ }^{\alpha}$ Médias não diferem do tratamento adicional pelo teste de Dunnett ao nível de 5\% de probabilidade

intermediárias e não diferiram estatisticamente destes. Este efeito pode ser resultado da interferência na reprodução dos nematoides.

O tratamento após a inoculação foi a única época na qual as vias de aplicação diferiram-se. A aplicação via foliar apresentou 69\% menos J2 e ovos por $100 \mathrm{~cm}^{3}$ de solo comparado à via solo, enquanto que a via solo+folha foi intermediária. As aplicações via foliar, tanto das épocas após a inoculação quanto semanalmente, reduziram $\mathrm{J} 2$ e ovos por 100 $\mathrm{cm}^{3}$ em $69,27 \%$ e $61,65 \%$ respectivamente comparado a testemunha.

No segundo experimento (Tabela 6), o tratamento após a inoculação na via solo+folha reduziu $\mathrm{J} 2$ e ovos por grama de raiz em $56,12 \%$ comparado à testemunha. Em aplicações semanais, as vias solo e solo+folha foram efetivas no controle, com redução de $49,10 \%$ e $79 \%$ em comparação à testemunha, respectivamente. Esse resultado confirma os resultados do primeiro experimento.

Assim como para J2 e ovos por grama de raiz, J2 e ovos por 100 $\mathrm{cm}^{3}$ de solo no segundo experimento (Tabela 6) não diferiram para as épocas de aplicação dentro de cada via. O tratamento via foliar semanalmente reduziu $50,35 \%$ os $\mathrm{J} 2$ e ovos por $100 \mathrm{~cm}^{3}$ de solo em comparação à testemunha, enquanto que tratamento via solo+folha após a inoculação foi inferior à testemunha em 54,23\% para J2 e ovos por $100 \mathrm{~cm}^{3}$ de solo.

Aplicações semanais via foliar somente reduziram J2 e ovos por 
$100 \mathrm{~cm}^{3}$ de solo (Tabela 6) em relação às demais variáveis analisadas. Isso pode ser devido a inviabilidade dos ovos (Tabela 7), por meio de mecanismos de defesa ativados na planta que poderiam criar um ambiente desfavorável à eclosão destes ou ao desenvolvimento dos J2 na raiz. Mecanismos de defesa podem ser ativados em raízes de tomateiro por meio de extratos vegetais (9).

Apesar de aplicações semanais via foliar não diferirem estatisticamente da via solo+folha (Tabela 6), o tratamento via foliar foi $38,32 \%$ inferior à via solo+folha para $\mathrm{J} 2$ e ovos por $100 \mathrm{~cm}^{3}$ de solo. Isto indica que a planta pode ter criado um ambiente desfavorável à formação dos ovos ou à alimentação das fêmeas pelas células nutridoras, resultando em menor viabilidade de ovos. Esses resultados podem ser confirmados pelo ensaio da viabilidade de massa de ovos (Tabela 7), na qual aplicações semanais do extrato de crambe via folha e via solo+folha foram inferiores que as mesmas vias após a inoculação. Na época semanal todas as vias diferiram da testemunha e não diferiram entre si.

\section{AGRADECIMENTOS}

A Coordenação de Aperfeiçoamento de Pessoal de Nível Superior (CAPES) pela concessão de bolsa de estudos e ao Conselho Nacional de Desenvolvimento Tecnológico (CNPq) pelo suporte financeiro.

\section{REFERÊNCIAS}

1. Aissani, N.; Tedeschi, P.; Maietti, A.; Brandolini, V.; Garau, V.L.; Caboni, P. Nematicidal activity of allylisothiocyanate from horseradish (Armoracia rusticana) roots against Meloidogyne incognita. Journal of Agricultural and Food Chemistry, Washington, v. 61, p.4723-4727, 2013.

2. Andrade, L.B.; Oliveira, A.S.; Ribeiro, J.K.C.; Kiyita, S.; Vasconcelos, I.M.; Oliveira, J.T.A.; Sales, M.P. Effects of a novel pathogenesis-related class 10 (PR-10) protein from Crotalaria pallida roots with papain inhibitory activity against root-knot nematode Meloidogyne incognita. Journal of Agricultural and Food Chemistry, Washington, v. 58, p. 4145-4152, 2010.

3. Babu, R.O.; Moorkoth, D.; Azeez, S.; Eapen, S.J. Virtual screening and in vitro assay of potential drug like inhibitors from spices against Glutathione-S-Transferase of Meloidogyne incognita. Bioinformation, Singapore, v. 8, n. 7, p. 319-325, 2012.

4. Caboni, P.; Saba, M.; Tocco, G.; Casu, L.; Murgia, A.; Maxia, A.; Menkisk soglu-Spiroudi, U.; Ntalli, N. Nematicidal activity of mint aqueous extracts against the root-knot nematode Meloidogyne incognita. Journal of Agricultural and Food Chemistry, Washington, v. 61, p. 9784-9788, 2013.

5. Cruz, C.D. Programa Genes: Biometria. Editora UFV. Viçosa (MG), 2006. $382 \mathrm{p}$.

6. Dong-Jun, S.; Dang-Minh-Chanh, N.; Ro-Dong, P.; Woo-Jin, J. Chitosane cinnamon beads enhance suppressive activity against Rhizoctonia solani and Meloidogyne incognita in vitro. Microbial Pathogenesis, London, v.66, p.44-47, 2014

7. Falasca, S.L.; Flores, N.; Lamas, M.C.; Carballo, S.M.; Anschau, A. Crambe abyssinica: an almost unknown crop with a promissory future to produce biodiesel in Argentina. International Journal of Hydrogen Energy, Oxford, v.35, p.5808-5812, 2010.
8. Franzener, G.; Unfried, J.R.; Stangarlin, J.R.; Furlanetto, C. Nematoides formaғ dores de galha e de cisto patogênicos à cultura da soja em municípios do oeste do Paraná. Nematologia Brasileira, Piracicaba, v.29, n.2, p.261-265, 2005.

9. Franzener, G.; Franzener, A.S.M.; Stangarlin, J.R.; Furlanetto, C.; Schwan-Estrada, K.R.F. Proteção de tomateiro a Meloidogyne incognita pelo extrato de Tagetes patula. Nematologia Brasileira, Piracicaba, v.31, n.1, p.27-36, 2007.

10. Freitas, L.G.; Neves, W.S.; Oliveira, R.D.L. Métodos em nematologia vegetal. In: Alfenas AC, Mafia RG. Métodos em fitopatologia. 2. ed. Viçosa: Ed. UFV, 2016. p. 257-295.

11. Jenkins, W.R. A rapid centrifugal-flotation technique for separating nematodes from soil. Plant Disease Reporter, St. Paul, v.48, p.692, 1964.

12. Leoni, O.; Iori, R.; Palmieri, S.; Esposito, E.; Menegatti, E.; Cortesi, R.; Nastruzzi, C. Myrosinase-generated isothiocyanate from glucosinolates: isolation, characterization and in vitro antiproliferative studies. Bioorganic \& Medicinal Chemistry, Oxford, v. 5, n. 9, p. 1799-1806, 1997.

13. Li, J.; Xu, H. Bioactive compounds from the bark of Eucalyptus exserta $\mathrm{F}$. Muell. Industrial Crops and Products, Amsterdam, v.40, p.302-306, 2012.

14. Loguercio, A.P.; Battistin, A.; Vargas, A.C.; Henzel, A.; Witt, N.M. Atividade antibacteriana de extrato hidro-alcoólico de folhas de jambolão (Syzygium cumini (L.) Skells). Ciência Rural, Santa Maria, v.35, n.2, p.371-376, 2005.

15. Mayton, H.; Olivier, C.; Vaughn, S.; Loria, R. Correlation of fungicidal activity of Brassica species with allyl isothiocyanate production in macerated leaf tissue. Phytopathology, St. Paul, v.86, p.267-271, 1996.

16. Morra, M.J.; Kirkegaard, J.A. Isothiocyanate release from soil-incorporated Brassica tissues. Soil Biology \& Biochemistry, Elmsford, v. 34, p. 16831693, 2002.

17. Molinari, S.; Baser, N. Induction of resistance to root-knot nematodes by SAR elicitors in tomato. Crop Protection, Amsterdam, v.29, p.1354-1362, 2010.

18. Oka, Y.; Cohen, Y. Induced resistance to cyst and root-knot nematodes in cereals by DL- $\beta$-amino- $n$-butyric acid. European Journal of Plant Pathology, London, v.107, p.219-227, 2001.

19. Oliveira, R.D.L.; Dhingra, O.D. Biofumigação com Brassica sp. para o controle de doenças de plantas. In: Venzon, M.; Paula Júnior, T.J.; Pallini, A. Avanços no controle alternativo de pragas e doenças. Viçosa: Ed. EPAMIG-CTZM, 2008. p.237-257.

20. Oliveira, R.D.L.; Dhingra, O.D.; Lima, A.O.; Jham, G.N.; Berhow, M.A.; Holloway, R.K.; Vaughn, S.F. Glucosinolate content and nematicidal activity of Brazilian wild mustard tissues against Meloidogyne incognita in tomato. Plant soil, The Hague, v.341, p.155-164, 2011.

21. Salgado, S.M.L.; Silva, L.H.C.P. Potencial da indução de resistência no controle de fitonematoides. In: Cavalcanti, L.S.; Di Piero, R.M.; Cia, P.; Pascholati, S.F.; Resende, M.L.V.; Romeiro, R.S. Indução de resistência em plantas a patógenos e insetos. Piracicaba: FEALQ, 2005. v.13, p.155-165.

22. Silva, M.B.; Rosa, M.B.; Brasileiro, B.G.; Almeida, V.; Silva, C.A. Desene volvimento de produtos à base de extratos de plantas para o controle de doenças de plantas. In: Venzon, M.; Paula Júnior, T.J.; Pallini, A. Controle alternativo de pragas e doenças. Viçosa: Ed. EPAMIG, 2005. p. 221-246.

23. Taylor, A.L.; Sasser, J.N. Biology, identification and control of root-knot nematodes (Meloidogyne sp.). Raleigh, Ed. North Carolina State University, 1978. $111 \mathrm{p}$.

24. Wu, H.; Wang, C.J.; Bian, X.W. B.; Zeng, S.Y.; Lin, K.C.; Wu, B.; Zhang, G.A.; Zhang, X. Nematicidal efficacy of isothiocyanates against root-knot nematode Meloidogyne javanica in cucumber. Crop Protection, Amsterdam, v. 30, p. 33-37, 2011. 